Fixed Point Theory, 20(2019), No. 1, 245-254

DOI: $10.24193 /$ fpt-ro.2019.1.16

http://www.math.ubbcluj.ro/ nodeacj/sfptcj.html

\title{
FIXED POINT ALGORITHMS FOR SPLIT FEASIBILITY PROBLEMS
}

\author{
A.E. AL-MAZROOEI*, A. LATIF**, X. QIN*** AND J.C. YAO**** \\ * Department of Mathematics, University of Jeddah \\ P.O. Box 80327, Jeddah 21589, Saudi Arabia \\ E-mail: aealmazrooei@uj.edu.sa \\ ** Department of Mathematics, King Abdulaziz University \\ Jeddah, Saudi Arabia \\ E-mail: alatif@kau.edu.sa \\ *** Corresponding author \\ Institute of Fundamental and Frontier Sciences \\ University of Electronic Science and Technology of China, Sichuan, China \\ E-mail: qxlxajh@163.com \\ **** Center for General Education, China Medical University \\ Taichung 40402, Taiwan \\ E-mail: yaojc@mail.cmu.edu.tw
}

\begin{abstract}
The purpose of the paper is to investigate a split feasibility problem based on a fixed point algorithm. A weak convergence theorem of solutions is established in the framework of infinite dimensional Hilbert spaces. As an application, a split equality problem is also investigated.

Key Words and Phrases: Hilbert space, monotone mapping, nonexpansive mapping, split feasibility problem, weak convergence.
\end{abstract}

2010 Mathematics Subject Classification: 47H05, 47H09, 47N10.

Acknowledgment. This work was supported by the Deanship of Scientific Research (DSR), University of Jeddah, Jeddah, Saudi Arabia under grant No. (UJ-05-18-ICP). The authors, therefore, gratefully acknowledge the DSR for technical and financial support.

\section{REFERENCES}

[1] Q.H. Ansari, A. Rehan, J.C. Yao, Split feasibility and fixed point problems for asymptotically $k$-strict pseudo-contractive mappings in intermediate sense, Fixed Point Theory, 18(2017), 5768.

[2] B.A. Bin Dehaish, et al., A regularization projection algorithm for various problems with nonlinear mappings in Hilbert spaces, J. Ineq. Appl., 2015(2015), Article ID 51.

[3] B.A. Bin Dehaish, et al., Weak and strong convergence of algorithms for the sum of two accretive operators with applications, J. Nonlinear Convex Anal., 16(2015), 1321-1336.

[4] F.E. Browder, Fixed-point theorems for noncompact mappings in Hilbert space, Proc. Nat. Acad. Sci. USA, 53(1965), 1272-1276. 
[5] F.E. Browder, Nonexpansive nonlinear operators in a Banach space, Proc. Nat. Acad. Sci. USA, 54(1965), 1041-1044.

[6] C.L. Byrne, A unified treatment of some iterative algorithms in signal processing and image reconstruction, Inverse Probl., 20(2004), 103-120.

[7] L.C. Ceng, Q.H. Ansari, J.C. Yao, Mann type iterative methods for finding a common solution of split feasibility and fixed point problems, Positivity, 16(2012), 471-495.

[8] Y. Censor, T. Bortfeld, B. Martin, A. Trofimov, A unified approach for inversion problems in intensity modulated radiation therapy, Phys. Med. Biol., 51(2006), 2353-2365.

[9] Y. Censor, T. Elfving, A multiprojection algorithm using Bregman projections in a product space, Numer. Algorithms, 8(1994), 221-239.

[10] S.S. Chang, L. Wang, Y. Zhao, On a class of split equality fixed point problems in Hilbert spaces, J. Nonlinear Var. Anal., 1(2017), 201-212.

[11] S.Y. Cho, Strong convergence analysis of a hybrid algorithm for nonlinear operators in a Banach space, J. Appl. Anal. Comput., 8(2018), 19-31.

[12] S.Y. Cho, B.A. Bin Dehaish, X. Qin, Weak convergence of a splitting algorithm in Hilbert spaces, J. Appl. Anal. Comput., 7(2017), 427-438.

[13] S.Y. Cho, W. Li, S.M. Kang, Convergence analysis of an iterative algorithm for monotone operators, J. Ineq. Appl., 2013(2013), Article ID 199.

[14] S.Y. Cho, Generalized mixed equilibrium and fixed point problems in a Banach space, J. Nonlinear Sci. Appl., 9(2016), 1083-1092.

[15] W.A. Kirk, A fixed point theorem for mappings which do not increase distances, Amer. Math. Monthly, 72(1965), 1004-1006.

[16] A. Moudafi, A relaxed alternating $C Q$ algorithm for convex feasibility problems, Nonlinear Anal., 79(2013), 117-121.

[17] A. Moudafi, E. Al-Shemas, Simultaneouss iterative methods forsplit equality problem, Tran. Math. Program. Appl., 1(2013), 1-11.

[18] Z. Opial, Weak convergence of the sequence of successive approximation for nonexpansive mappings, Bull. Amer. Math. Soc., 73(1967), 591-597.

[19] X. Qin, S.Y. Cho, L. Wang, Strong convergence of an iterative algorithm involving nonlinear mappings of nonexpansive and accretive type, Optimization, 67(2018), 1377-1388.

[20] X. Qin, A. Petruşel, J.C. Yao, CQ iterative algorithms for fixed points of nonexpansive mappings and split feasibility problems in Hilbert spaces, J. Nonlinear Convex Anal., 19(2018), 157-165.

[21] X. Qin, J.C. Yao, Projection splitting algorithms for nonlinear operators, J. Nonlinear Convex Anal., 18(2017), 925-935.

[22] S. Reich, Weak convergence theorems for nonexpansive mappings in Banach spaces, J. Math. Anal. Appl., 75(1979), 274-276.

[23] J. Tang, S.S. Chang, J. Dong, Split equality fixed point problems for two quasi-asymptotically pseudocontractive mappings, J. Nonlinear Funct. Anal., 2017(2017), Article ID 26.

[24] L. Wei, R.P. Agarwal, Relaxed iterative methods for an infinite family of d-accretive mappings in a Banach space and their applications, J. Nonlinear Funct. Anal., 2018(2018), Article ID 16.

[25] W. Takahashi, Nonlinear Functional Analysis, Yokohama Publishers, Yokohama, 2000.

Received: June 14, 2017; Accepted: February 10, 2018. 